\title{
Modal Analysis of Bleed Air System based on NASTRAN
}

\author{
Juan LIU \\ Shanghai Aircraft Design \&Research Institute, Shanghai, 200232, China \\ chris-liujuan2007@163.com
}

Keywords: Bleed air system, Modal analysis, NASTRAN.

Abstract. Based on the analysis of structure composition, material properties, operating conditions of bleed air system, a finite element model is developed and the natural frequencies and vibration modes are obtained by NASTRAN. The results show that the first ten natural frequencies comparatively dense, each order natural frequency in operating state are lower than the corresponding frequency in non-operating state. The deformations are mainly concentrated in the APU pipe and the two branches arranged with concentrated mass components, and the maximum deformation positions under the two states are different in the same order. This work can assist in design of civil-aircraft bleed air system and similar high temperature and high pressure duct system.

\section{Introduction}

Bleed air system originates air from air sources and supplies with controlled temperature and pressure via a manifold connected to aircraft system users, including engine starters, air conditioning system, anti-ice system, etc ${ }^{[1]}$. Bleed air system is flexible within high temperature and high pressure air. The bending moment and shear force generated by bend, acceleration, airflow and the vibration transferred from engines and other transmission parts can affect the system dynamic performance. If the external vibration frequency is equal or close to the natural frequency, resonance occurs. That influences the performance of bleed air system and brings noise, accelerates component fatigue damage, reduces insulation performance, damages sealing member, etc. Based on the analysis of structure composition, material properties, operating conditions, a shell element model of bleed air system is developed and the natural frequencies and vibration modes in non-operating and operating state are obtained. This work can provide advices for civil-aircraft bleed air system and similar high temperature and high pressure duct system design.

\section{Model Analysis Theory}

The four basic components of dynamic system are mass, energy dissipation, elastic resistance and external load. The kinetic differential equation with multi-degree of freedom is given as Eq. 1.

$$
[\mathrm{M}]\{\ddot{\mathrm{X}}\}+[\mathrm{C}]\{\dot{\mathrm{X}}\}+[\mathrm{K}]\{\mathrm{X}\}=\{\mathrm{F}(\mathrm{t})\}
$$

Where $[\mathrm{M}]$ is the mass matrix, $[\mathrm{C}]$ is the damping matrix, $[\mathrm{K}]$ is the stiffness matrix, $\{\ddot{\mathrm{X}}\}$ is the acceleration, $\{\dot{\mathrm{X}}\}$ is the velocity, $\{\mathrm{X}\}$ is the displacement, $\{\mathrm{F}(\mathrm{t})\}$ is the force vector. If there is no external force and the damping is little enough to be ignored, the equation can be shown as Eq. 2 .

$$
[\mathrm{M}]\{\ddot{\mathrm{X}}\}+[\mathrm{K}]\{\mathrm{X}\}=\{0\}
$$

And the corresponding eigenvalue equation is Eq. 3.

$$
\left([\mathrm{K}]-\omega^{2}[\mathrm{M}]\right)\{\mathrm{X}\}=\{0\}
$$

Where $\omega$ is the natural frequency. The natural frequency can be obtained by solving Eq. $3^{[2,3]}$. 


\section{Bleed Air System}

Bleed air system structure is complex due to the requirements of manufacture, thermal insulation, space limitation, etc. According to the SAE ARP699 and ASME specifications, lots of compensation and restriction mechanisms such as ball joint, saddle clamp, sliding seal, flange, anchor and air handling equipments such as valve, filter and ozone generator are used, as shown in Fig. 1. Bleed air system manages air source selection from the engines, the auxiliary power unit (APU) or the external high pressure ground cart (HPGC). Considering the needs of aircraft systems, an air source meeting with the real state of aircraft and power plant is selected, and the corresponding temperature and pressure can be controlled by adjusting the opening state of valves. The distribution of valves divides bleeds air system into 8 zones.

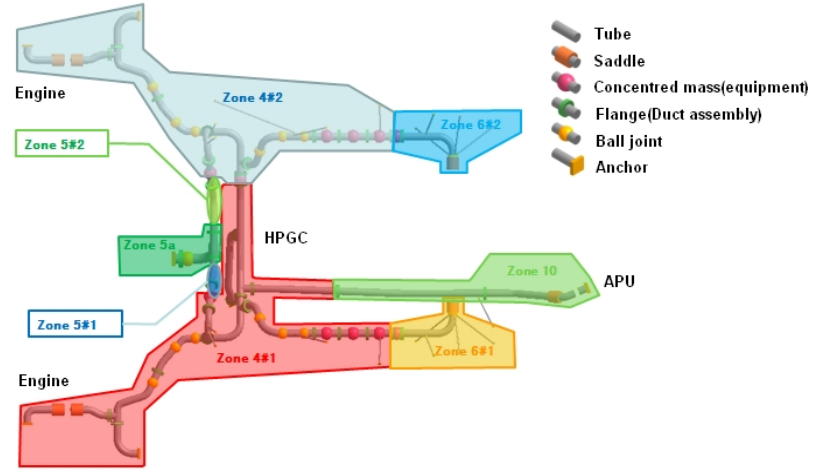

Fig. 1 Structure of bleed air system

\section{Model}

\section{Simplifications and Assumptions}

The premise of modal analysis is to establish a reasonable finite element model. Thin-wall duct as the main structure and take full account of mass distribution, the shell element model of bleed air system is established. And some assumptions should be given before analysis ${ }^{[4]}$.

(1) Continuity assumption. The materials of ducts and accessories are dense with no gap in the whole volume, and can be described by the continuous function.

(2) Zero initial stress and zero volume force assumptions.

(3) Isotropic assumption. The mechanical properties of material in all directions are the same.

(4) The influences of insulation layer and other leak detection apparatus can be ignored.

\section{Simulation of Key Components}

Due to the complex structure, it is hard to establish the whole shell element models for all flanges, lugs, ball joints, etc. These components are simplified by functional simulation to reflect their effects on duct system.

(1) Lug. Lug plays a role of weight supporting, displacement deformation limitation and vibration protection. It can be modeling by a rod element by releasing three rotational degrees of freedom and constraining three translational degrees of freedom on both ends.

(2) Saddle clamp. Saddle clamp is mainly used for fixing duct to aircraft structure and avoiding lateral deflection. It can be simulated by RBE3 by releasing axial movement and three rotational degrees of freedom and constraining two lateral translational degrees of freedom.

(3) Ball Joint. Ball joint has lateral rotational degrees of freedom under bending moment, and can be simulated by multi-point constraints and a spring unit.

(4) Sliding seal. Sliding seal is simulated as a free end, and its compensation capacity can be checked by the displacement of the duct at the location of sliding seal.

(5) Flange, valve, air handling equipment. These components are connecting piece, which can be modeling by a concentrated mass.

(6) Anchor. Anchor is simulated as a fixed end for supporting system and isolating displacement. 


\section{Shell Element Model}

(1) Material Properties. The duct of bleed air system are composed by A312 TP321stainless steel, the lug is composed by $2042 \mathrm{~T} 42$ aluminum tube. The properties at typical temperatures are shown in Table 1, and at other temperatures can be obtained by linear extrapolation.

Table 1 Material properties

\begin{tabular}{|c|c|c|c|c|c|c|c|}
\hline Material & $\mathrm{T}\left[{ }^{\circ} \mathrm{C}\right]$ & $\mathrm{E}[\mathrm{MPa}]$ & $\alpha\left[\mathrm{mm} / \mathrm{mm} /{ }^{\circ} \mathrm{C}\right]$ & $\mathrm{F}_{\mathrm{TU}}[\mathrm{MPa}]$ & $\mathrm{F}_{\mathrm{TY}}[\mathrm{MPa}]$ & $\rho\left[\mathrm{kg} / \mathrm{m}^{3}\right]$ & $\begin{array}{c}\text { Poisson } \\
\text { ratio }\end{array}$ \\
\hline \multirow{2}{*}{$\mathrm{A} 312$} & 20 & 200000 & $17.50 \times 10^{-6}$ & 665 & 200 & & \multirow{2}{*}{7900} \\
\cline { 2 - 6 } $\mathrm{TP} 321$ & 200 & 191000 & $18.00 \times 10^{-6}$ & 515 & 152 & 0.3 \\
\cline { 2 - 6 } & 300 & 184000 & $18.50 \times 10^{-6}$ & 490 & 147 & & \\
\hline \multirow{2}{*}{$2042 \mathrm{~T} 42$} & 20 & 75200 & - & 393 & 234 & 2800 & 0.33 \\
\hline
\end{tabular}

(2) Material Constitutive Relation. The accuracy of calculation results is largely determined by the stress-strain relationship and the mechanical properties of material ${ }^{[5]}$. The stress-strain curves of the steel are shown in Fig. 2, and the curves at other temperatures can be obtained by linear interpolation.

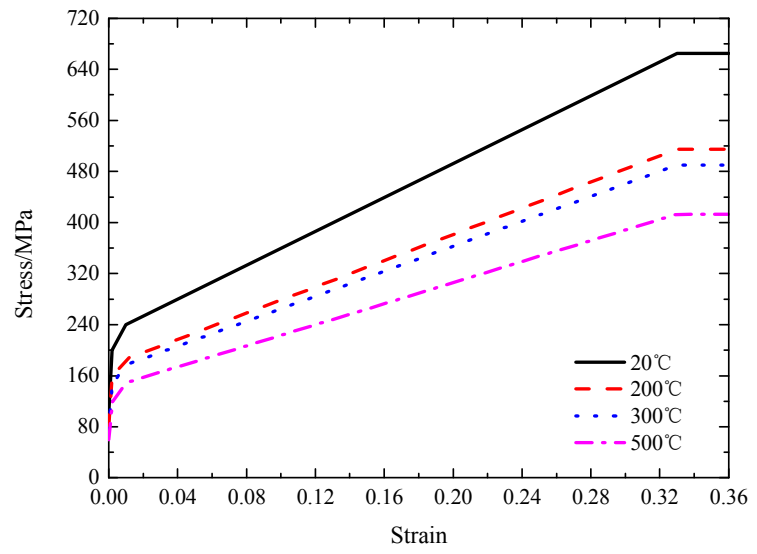

Fig 2 Stress-strain curves of steel

(3) Meshing. The quadrilateral shell finite element model of bleed air system is produced by PATRAN, as shown in Fig. 3. The nodes of bleed air system are 61936 and the elements are 61301.

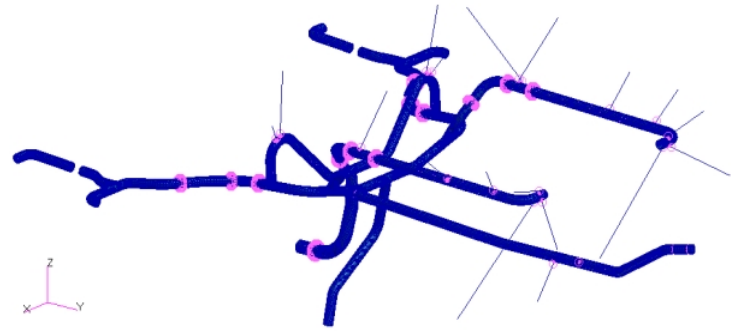

Fig. 3 Finite element model of bleed air system

(4) Boundary Conditions. The natural frequency is directly related to structure rigidity, the greater the stiffness, the higher the natural frequency. In addition to the diameter, wall thickness, direction of ducts, the system stiffness is also influenced by the temperature and pressure of flow in ducts. The reason is that the elastic modulus of material is related to temperature, and temperature and pressure acting on structure can change the bending and torsion stiffness ${ }^{[6]}$. So it is necessary to consider the natural frequency of bleed air system in non-operating and operating state at the beginning of system design. Air source selection and opening state of valves jointly determine the temperature and pressure distribution under each operating condition. Choose one for analysis, the temperature and pressure of each area are shown in Table 2. 
Table 2 Temperature and pressure of each region

\begin{tabular}{|c|c|c|c|c|c|}
\hline Zone & $\mathrm{T}\left[{ }^{\circ} \mathrm{C}\right]$ & $\mathrm{P}[\mathrm{MPa}]$ & Zone & $\mathrm{T}\left[{ }^{\circ} \mathrm{C}\right]$ & $\mathrm{P}[\mathrm{MPa}]$ \\
\hline Zone 4\#1 & 260 & 0.041 & Zone 5a & 232 & 0.028 \\
\hline Zone 4\#2 & 260 & 0.041 & Zone 6 \#1 & 232 & 0.028 \\
\hline Zone 5\#1 & 232 & 0.028 & Zone 6\#2 & 232 & 0.028 \\
\hline Zone 5\#2 & 232 & 0.028 & Zone 10 & 40 & 0 \\
\hline
\end{tabular}

\section{Results}

According to the modal analysis of bleed air system in non-operating and operating state, the first ten order natural frequencies are obtained in Table 3, and the first five order natural vibration modes are shown in Fig. 4.

Table 3 The first ten order natural frequencies of bleed air system

\begin{tabular}{|c|c|c|c|c|c|}
\hline \multirow{2}{*}{ Order } & \multicolumn{2}{|c|}{ Frequency[Hz] } & \multirow{2}{*}{ Order } & \multicolumn{2}{c|}{ Frequency[Hz] } \\
\cline { 2 - 3 } & Non-operating & Operating & & Non-operating & Operating \\
\hline 1st & 14.494 & 7.186 & 6th & 26.260 & 16.881 \\
\hline 2nd & 15.097 & 7.400 & 7th & 26.517 & 18.749 \\
\hline 3rd & 17.623 & 7.491 & 8th & 31.427 & 21.470 \\
\hline 4th & 19.763 & 12.860 & 9th & 32.815 & 26.264 \\
\hline 5th & 21.662 & 15.172 & 10th & 34.311 & 27.517 \\
\hline
\end{tabular}

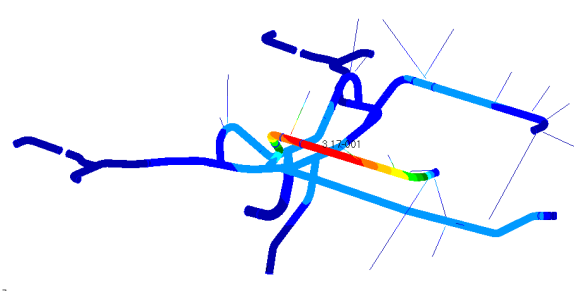

(a) 1 st order in non-operating state

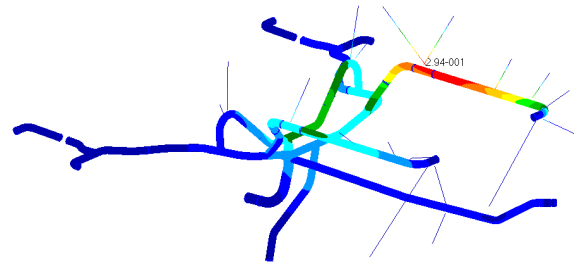

(c) 2nd order in non-operating state

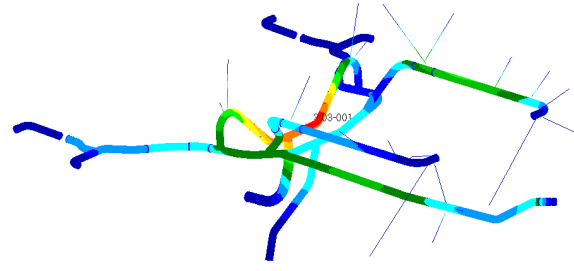

(e) 3rd order in non-operating state

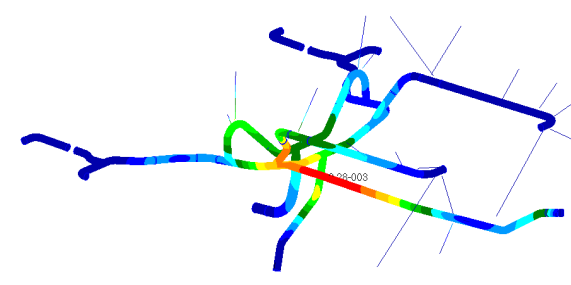

(b) 1 st order in operating state

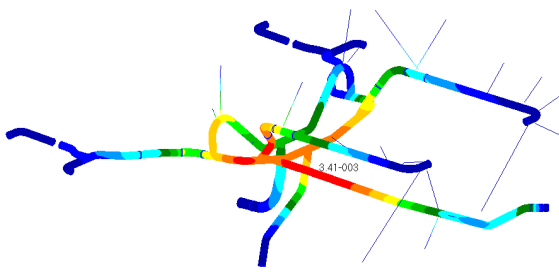

(d) 2nd order in operating state

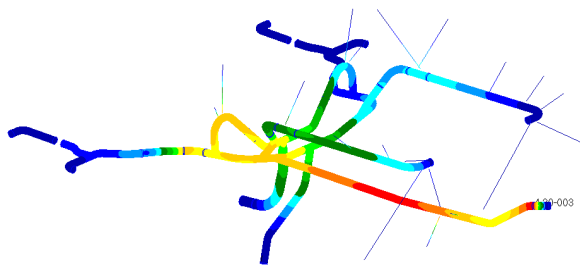

(f) 3rd order in operating state
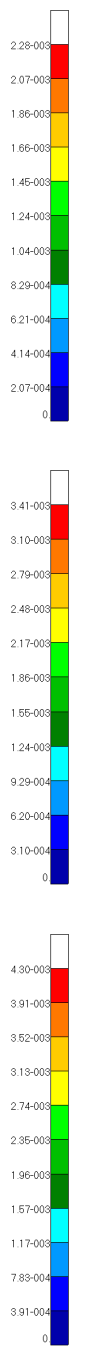


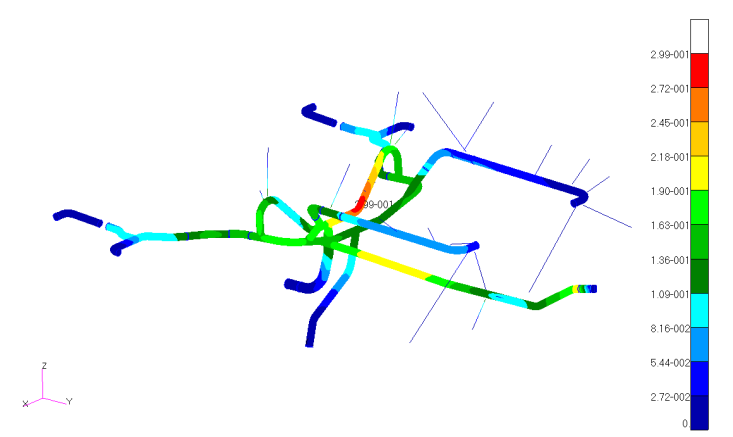

(g) 4th order in non-operating state

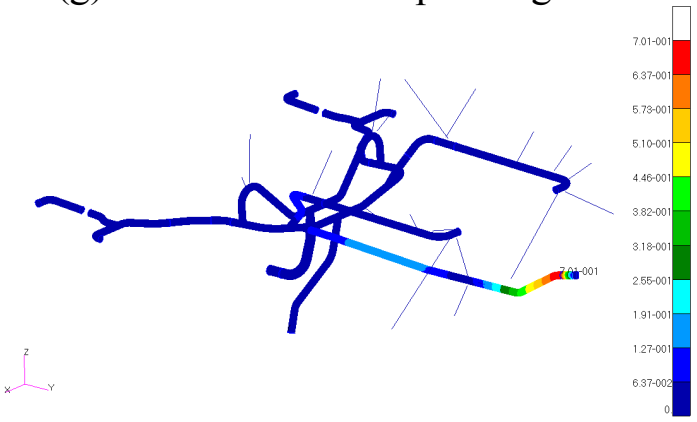

(i) 5th order in non-operating state

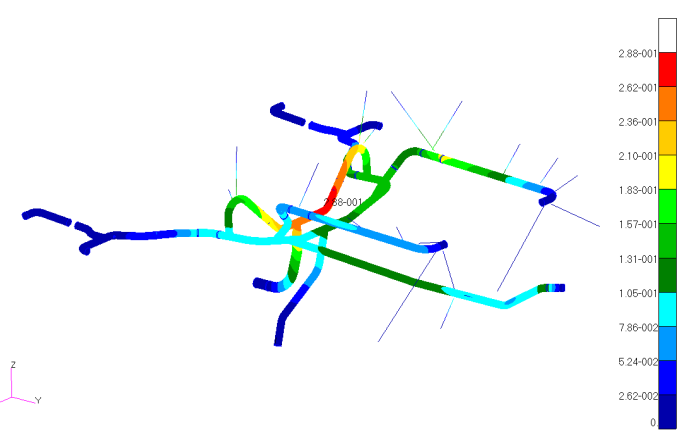

(h)4th order in operating state

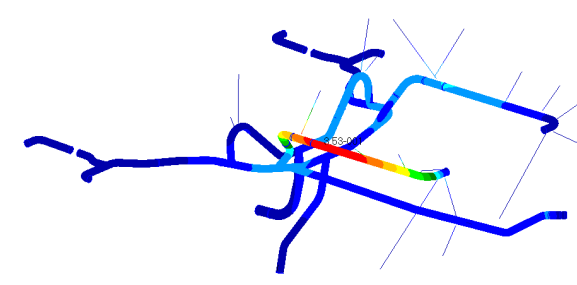

(j) 5th order in operating state

Fig. 4 Mode shapes of bleed air system

The results show that the first ten order natural frequencies of bleed air system are concentrated, and each order natural frequency in operating state is lower than the corresponding order in non-operating state. The vibration modes of bleed air system are mainly concentrated in the APU pipeline and the two branches with concentrated mass components, but the maximum vibration parts in the two states are different in the same order. The cause is that the high temperature and high pressure within the ducts can bring about two aspects of the effect. One is the elastic modulus decreases with the increase of temperature. The other is the high temperature and high pressure acting on structure can change the bending and torsion stiffness of the structure. At the beginning of the design of bleed air system, the effects of temperature and pressure under various operating conditions on the natural frequency should be considered to avoid resonance.

\section{Conclusions}

In this paper, the shell element model of bleed air system is established by NASTRAN based on the investigation of structure composition, material properties and operating conditions. The natural frequencies and vibration modes in both non-operating state and operating state are obtained. The analysis results present that the natural frequency and the maximum vibration part in the same order in non-operating state and operating state are different. At the beginning of design of bleed air system, the effects of high temperature and high pressure under various operating conditions on the natural frequency should be considered to avoid resonance. This work can assist in design of civil-aircraft bleed air system and similar high temperature and high pressure duct system.

\section{References}

[1] Yongbo He, Yanhui Yang. Modeling and fault simulation of aircraft pneumatic system[J]. Computer Applications and Software, 2013, 30(10): 220-303.

[2] Mechel F.P. Modal-analysis in curved and ring-shaped ducts[J]. Acta Acustica United With Acustica, 2008,94(2):173-206.

[3] Ping Du, Xiaxia Hu. Modal Analysis of Pipeline Systems[J]. Light Industry Machinery, 2012, 30(3): 29-33. 
[4] Na Liu. The Study on Simplized Stress Analysis Model for Industry Pressure Piping [D]. Beijing University of Chemical Technology, 2005, (01).

[5] Zhiwei Deng. Analysis on the operating conditions and material requirements of the pressure pipe[J]. Pipeline Technique and Equipment, 2009 (004): 18-20.

[6] Zhibin Yang, Hai Zhou, Dong Zhou. Thermal mode analysis of engine inlet[J]. Aeronautical Computing Technique, 2011, 41(5): 65-67. 